Génét. Sél. Evol., 1987, 19 (4), 427-444

\title{
Intra- and intergenotypic larval competition in Drosophila melanogaster : effect of larval density and biotic residues
}

\author{
J.A. CASTRO, Luisa M. BOTELlA * and J.L. MENSUA \\ Departamento de Genética, Facultad de Biología, Universidad de Valencia, \\ Dr. Moliner 50, 46100 Burjassot, Valencia, Spain
}

\begin{abstract}
Summary
Optimal density (maximum adult production) was determined in 8 strains of Drosophila melanogaster reared on small amounts of food. The amount of uric acid excreted by each strain into the medium was also determined, as well as the resistance to toxic products (urea and uric acid) added to the media.

Competitive dicultures between these strains were later established so that the total seeding density corresponded to optimal densities of each competitor. In these competitive systems, regressions higher than first order were found. The outcome for viability and developmental time in dicultures is explained in terms of the parameters studied in the monocultures : viability, developmental time, intrinsic mortality, optimal density, excretion of uric acid, and resistance to biotic wastes.
\end{abstract} sidues.

Key words : Drosophila melanogaster, viability, developmental time, competition, biotic re-

\section{Résumé}

Compétition larvaire intra- et intergénotypique chez Drosophila melanogaster : effet de la densité larvaire et des résidus biologiques

La densité optimale (définie comme la production maximale d'adultes) a été déterminée pour 8 génotypes de Drosophila melanogaster cultivés sur des petites quantités d'aliment. La quantité d'acide urique excrétée dans le milieu de culture par chaque génotype a été déterminée ainsi que leur résistance aux produits toxiques (urée et acide urique) additionnés à l'aliment.

La compétition entre ces génotypes a été étudiée dans des cultures mixtes de telle sorte que la densité larvaire corresponde à la densité optimale de chaque compétiteur. Dans ces cultures mixtes, la viabilité larvo-nymphale et la durée de développement de chaque génotype varient en fonction de sa fréquence, selon une régression non toujours linéaire. Les performances des génotypes en cultures mixtes sont expliquées en fonction des paramètres étudiés en monocultures (viabilité, durée de développement, mortalité intrinsèque, densité optimale, excrétion d'acide urique et résistance aux résidus biologiques).

Mots clés : Drosophila melanogaster, viabilité, durée de développement, compétition, résidus biologiques.

* Present address : Institute of Genetics, University of Lund, Sölvegatan 29, S-22362, Lund, Sweden. 


\section{Introduction}

Frequency-dependent selection is a well-known phenomenon (Clarke \& O'Donald, 1964 ; Ayala \& Campbell, 1974 ; Debenedictis, 1977 ; Mather \& Caligari, 1981, 1983). It allows populations to establish allelic equilibria and explains the existence of stable polymorphisms reducing the segregational load (Tosic \& AYALA, 1981).

Frequency-dependent selection, in general, has been demonstrated by fitting linear regressions to the parameters of biological fitness studied (mainly viability and developmental time), as functions of genotypic frequencies of 2 competing species or strains. Interestingly, statistical analyses have mainly employed first order regressions, and the linear fits have been applied not only to 2 competitors but also to monocultures, in spite of the fact that several monoculture studies might fit non-linear regressions. Apparently studies finding non-linear regressions are not taken into consideration for the lack of a clear biological explanation (CALIGARI, 1980). Actual experimental evidence shows that viabilities and developmental times do not fit always linear regressions, but also second and higher order regressions in mono- and dicultures (MoyA, 1983 ; CASTRo et al., 1985).

A potentially important concept is that of « optimal density " (WILSON, 1980 ; WALlACE, 1981). On the assumption of the existence of unit biological spaces (WAllace, 1981 ; Moya \& CASTRO, 1986), as density increases the spaces will be occupied until they are all filled. Once filled, optimal density will have been reached and, therefore, maximum adult production. From this point on there will be more individuals than unit spaces and, consequently a greater struggle for food and space among larvae. Other factors may also be critical, including the increasing presence of larval biotic residues (Lewontin, 1955 ; Huang et al., 1971 ; Palabost, 1973 ; Dolan \& RoBERTSON, 1975) which will generally cause a drastic drop in viability and a lengthening of developmental time (Botella et al., 1985 ; Castro et al., 1986), and intrinsic mortality (defined as the natural mortality occurring in non-competing populations (Moya \& CASTro, 1986).

Using intrinsic mortality and optimal density the response of strains in monocultures can be explained. Nevertheless, when strains compete with each other, intergenotypic coefficients appear, and the outcome of competition is not always predictable from the response of the strains in monocultures.

The purpose of the present work is to demonstrate the importance of optimal density (a reflection of the number of unit biological spaces) in the understanding of intra- and intergenotypic competition systems. It is also to determine the differential effects of uric acid and urea on genotypes. The effect of these residues on viability and developmental time is investigated in different strains, and their amount in competitive conditions was determined since these residues (mainly uric acid) are felt to be partially responsible for the outcome of the competition process, as demonstrated by CASTRo et al., 1986). 


\section{Materials and methods}

\section{A. Strains and vials}

Both natural and laboratory strains were used in these experiments. Each of the natural strains originated as progeny of a single captured female. They included a wild strain, as well as cardinal ( $\left.\mathrm{cd}^{770}, 3: 75.7\right)$, sepia $\left(\mathrm{se}^{700}, 3: 26.0\right)$, safranin $\left(\mathrm{sf}^{81 \mathrm{~m}}, 2: 71.5\right)$, and vermilion $\left(\mathrm{v}^{790}, 1: 33.0\right)$ mutant strains (NAJERA, 1985). The laboratory strains were Oregon-R (Or-R), isogenic Oregon-R (Iso-Or), and cinnabar (cn, 2:57.5).

Crowded cultures were raised in $5 \times 0.8 \mathrm{~cm}$ vials with $0.75 \mathrm{ml}$ of a boiled medium (consisting of water, 10 p. 100 sugar, 1 p. 100 agar, 0.5 p. 100 salt and 10 p. 100 brewer's yeast). Non-crowded cultures were reared in $10 \times 2.5 \mathrm{~cm}$ vials containing 10 $\mathrm{ml}$ of the same medium. Newly emerged larvae ( \pm 2 hour old) were sown into the vials. The cultures were maintained under constant light at a temperature of $25 \pm 1{ }^{\circ} \mathrm{C}$, and at $60 \pm 5$ p. 100 relative humidity.

\section{B. Larval collection}

Adults were transferred from a serial transfer system to bottles with fresh food for $24 \mathrm{~h}$. Afterwards, the adults were placed on egg-collecting devices (layers) for $12 \mathrm{~h}$. Each layer consisted of a glass receptacle which contains the flies, this receptacle being covered by a watch glass containing a mixture of agar, water, acetic acid and ethyl alcohol, with a drop of active yeast on it. The eggs are laid onto the surface of this mixture. Afterwards, the agar was cut into pieces containing from 150 to 200 eggs and each was placed in $150 \mathrm{ml}$ bottles with $30 \mathrm{ml}$ fresh food. When the adults which emerged were 5 days old, they were transferred to new fresh food bottles for $48 \mathrm{~h}$. They were then placed in layers for $2 \mathrm{~h}$. The watch glasses of the layers were kept for at least $18 \mathrm{~h}$ in petri dishes at $25^{\circ} \mathrm{C}$ until larvae hatched. These larvae were used in the experiments.

\section{Optimal densities}

In crowded vials increasing larval densities $(5,20,35,50,65,80,95,110$ and 125) were seeded. At least 5 replications were made for each strain at each density. Adults emerged from each vial were counted daily until the exhaustion of cultures. Viability and developmental time were used as parameters. The following arc sine transformation was applied to viability :

$$
\mathrm{V}=\operatorname{arcsine} \sqrt{\left(\mathrm{n}_{\mathrm{A}}+0.375\right) /\left(\mathrm{N}_{\mathrm{L}}+0.75\right)}
$$

where $n_{A}$ is the number of emerged adults when $N_{L}$ larvae are sown. In this case, the angular transformation is employed with some modifications; 0.375 is added to the numerator and 0.75 to the denominator. ANScombe (1948) suggested this expression when $\mathrm{N}_{\mathrm{L}}$ can be small. The developmental time was calculated according to the expression :

$D T=\Sigma\left(n_{i} \times d_{i}\right) / \Sigma n_{i}$, where $n_{i}$ is the number of adults emerged at the $d_{i}$ th day after seeding. 
Data for viability and developmental time were subjected to a polynomial regression analysis for which analysis of variance (ANOVA) was used to find the best fits of these curves as seeding density functions (SNEdeCor \& Cochran, 1981). This method permits location of the best polynomial regression from a statistical point of view.

From the polynomial regression equation for viability, optimal density was determined for each strain using the following formula :

$$
\text { arcsine } \sqrt{\left(\mathrm{n}_{\mathrm{A}}+0.375\right) /\left(\mathrm{N}_{\mathrm{L}}+0.75\right)}=\mathrm{a}+\mathrm{b}_{1}\left[\left(\mathrm{~N}_{\mathrm{L}} / 72\right) 100\right]+\mathrm{b}_{2}\left[\left(\mathrm{~N}_{\mathrm{L}} / 72\right) 100\right]^{2}+\cdots
$$

Optimal density was deduced from the maximum of the function :

$$
\mathrm{n}_{\mathrm{A}}=\left(\mathrm{N}_{\mathrm{L}}+0.75\right) \sin ^{2}\left(\mathrm{a}+\mathrm{b}_{1}\left[\left(\mathrm{~N}_{\mathrm{L}} / 72\right) 100\right]+\mathrm{b}_{2}\left[\left(\mathrm{~N}_{\mathrm{L}} / 72\right) 100\right]^{2}+\cdots\right)-0.375
$$

and was determined by numerical calculation. The number 72 which appears in the formulas is arbitrary. It is a consequence of the computer program employed in the determinations of polynomial regressions. It does not affect the accuracy of the regressions.

\section{Competition systems}

Taking as the total seeding densities the optimal densities calculated for each strain, seven frequency points were chosen for each competition system (see figure 1). When the competing strains had different optimal densities, 2 sets of experiments were carried out, one for each optimal density. In this way at least 5 replications were carried out in each of the 6 systems. Simultaneously with the experiments of competition systems, the same experiments described before to determine the optimal densities were carried out again to recalculate optimal densities for each strain. The purpose was to test whether the optimal densities were constant or changing over time.

In dicultures, employing a statistical method similar to that employed in section $\mathrm{C}$ with monocultures, analyses of variance completed with polynomial regressions were calculated for both viability and developmental time to find the best fits of these curves as seeding frequency functions. As before, this method also permits location of the best polynomial regression from a statistical point of view. In some cases, when a polynomial regression fit to data was not possible, the mean value of the data was taken.

The polynomial regressions in dicultures have the following general formula :

$$
\mathrm{Y}=\mathrm{a}+\mathrm{b}_{1}(\mathrm{Fr})+\mathrm{b}_{2}(\mathrm{Fr})^{2}+\ldots
$$

where

$\mathrm{Y}=$ viability (transformed to arcsine) or mean developmental time (in days), for each genotype ; and $F r$ is the frequency (in percentage) of each genotype, in each genotypic composition and in each competition system.

\section{E. Quantitative analysis of uric acid content}

Quantitative analyses of uric acid content in larvae, pupae and media in crowded cultures and in larvae and pupae from non-crowded cultures were carried out using the methods described by Botella et al. (1985) and CASTro et al. (1986). 


\section{F. Media supplemented with uric acid and urea}

In order to study the effect of uric acid upon viability and developmental time for each strain, non-crowded vials were supplied with $10 \mathrm{ml}$ of media supplemented with $10 \mathrm{mg} / \mathrm{ml}$ or $15 \mathrm{mg} / \mathrm{ml}$ of uric acid, and similarly for urea. A total of 72 larvae were placed in each vial. These concentrations were used, since Botella et al. (1985) showed that $10 \mathrm{mg}$ or more were appropriate for studying a uric acid or urea effect (CASTRO et al., 1986). A total of 10 replications were made. All emerged adults were counted daily until the exhaustion of the cultures.

III. Results

Polynomial fits for viability and developmental time as well as the optimal density for each strain are shown in table 1. As can be seen in this table, second and higher order fits in addition to linear fits were found for viability and developmental time. These regressions provide evidence that fits are nor necessarily linear, and may be more complicated as a result of facilitation or mutual cooperation among larvae, particularly at low densities (Lewontin, 1955). In this table, (1) gives the polynomial regressions found in the first determination, and (2) gives the polynomial regressions found in the second determination carried out simultaneously with the competition system. Over the optimal density point, these non-linear fits can be explained in terms of an additional phenomenon of competition. Some strains at high competition densities may enter a very restrictive competitive situation or even the so-called " chaos zone " (HASSEll et al., 1976) ; that is, crowding is so heavy that it induces in larvae a stress in their struggle for food and space. In this situation, populations do not behave predictably. Moreover, one can see that optimal densities vary from strain to strain, which indicates that differences exist in the resource utilization by larvae from different strains.

The optimal densities calculated in the 1st determination [(1) in table 1] were used to determine seeding numbers in competitive systems carried out later. When the determination of optimal density was carried out simultaneously with competition systems, regression fits higher than 1st order also appeared, even in those strains which previously fitted well to linear regressions. At the same time, variation in optimal density points took place. This might be due to a change in the strategy of strains over time, or to a change in the genetic composition of populations (Lewontin, 1985).

Figure 1 (a to $\mathrm{f}$ ) shows the graphs corresponding to the different competitive systems. The exclusion of one strain by the other seemed to prevail, though frequencydependent selection in viability and developmental time without equilibrium points occurred often. Frequency dependence is not always linear, but 2nd and 3rd degree polynomial regressions are also found (CASTRo et al., 1985). These functions might give rise to more than one point of equilibrium in competitive systems (though this was not our experience). As can be seen, in figure 1 in the wild/cinnabar system at a seeding density of 74 , one point of stable equilibrium arose at a frequency of $64 / 10$; and with a seeding density of 56 , at the frequency of $2 / 54$ in the Or-R/sf $\mathrm{s}^{81 \mathrm{~m}}$ system. 


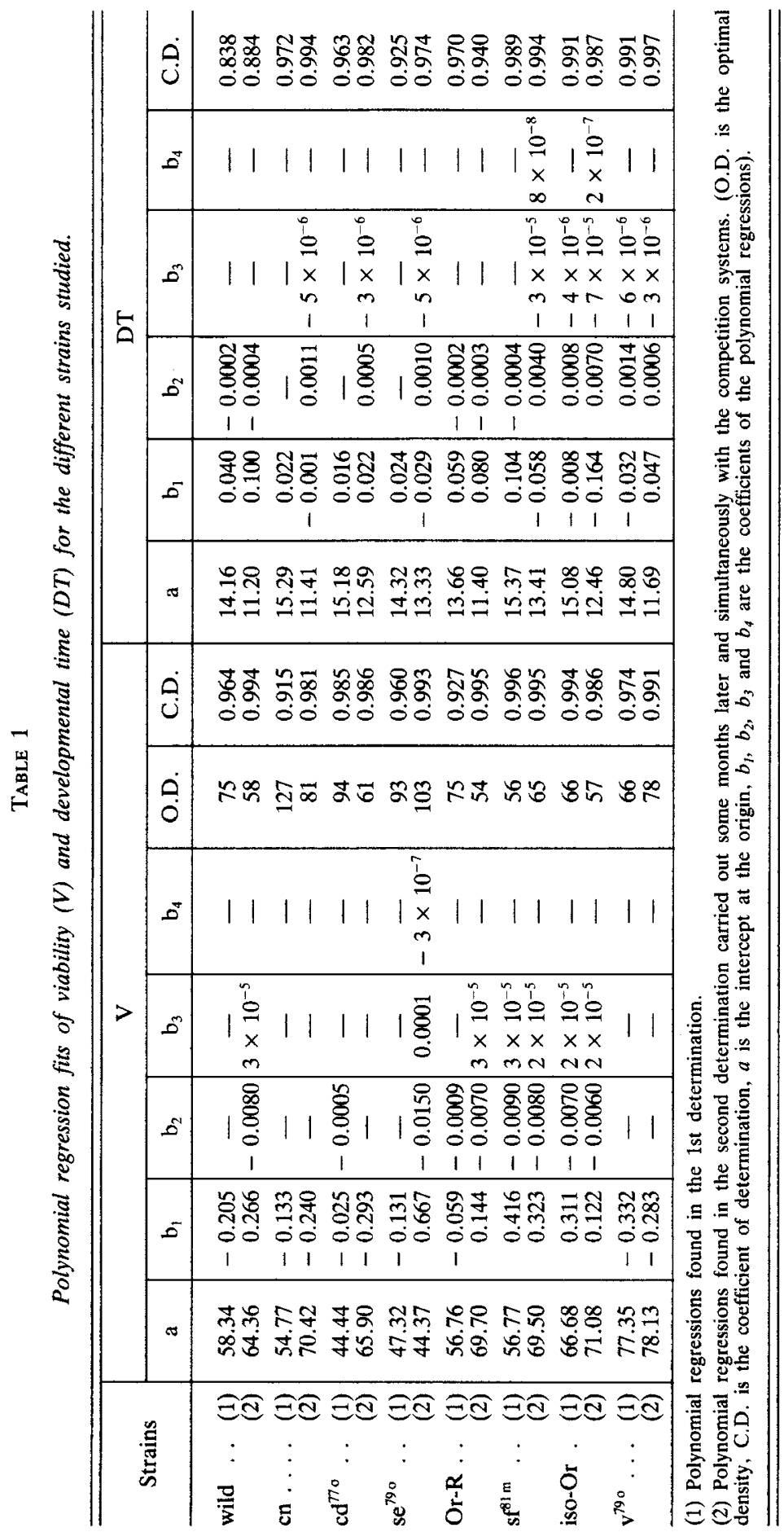



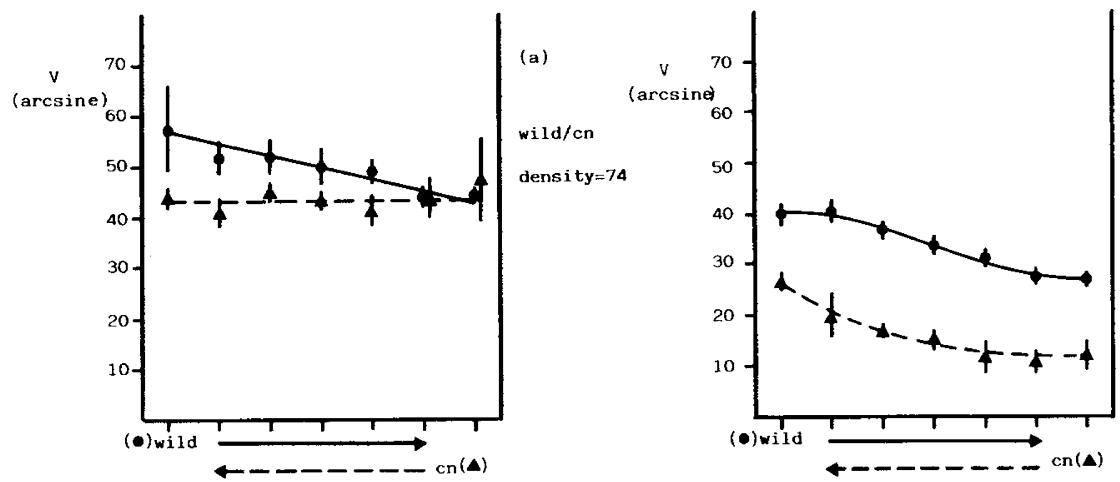

(b)

wild/cn

densi $\operatorname{ty}=126$
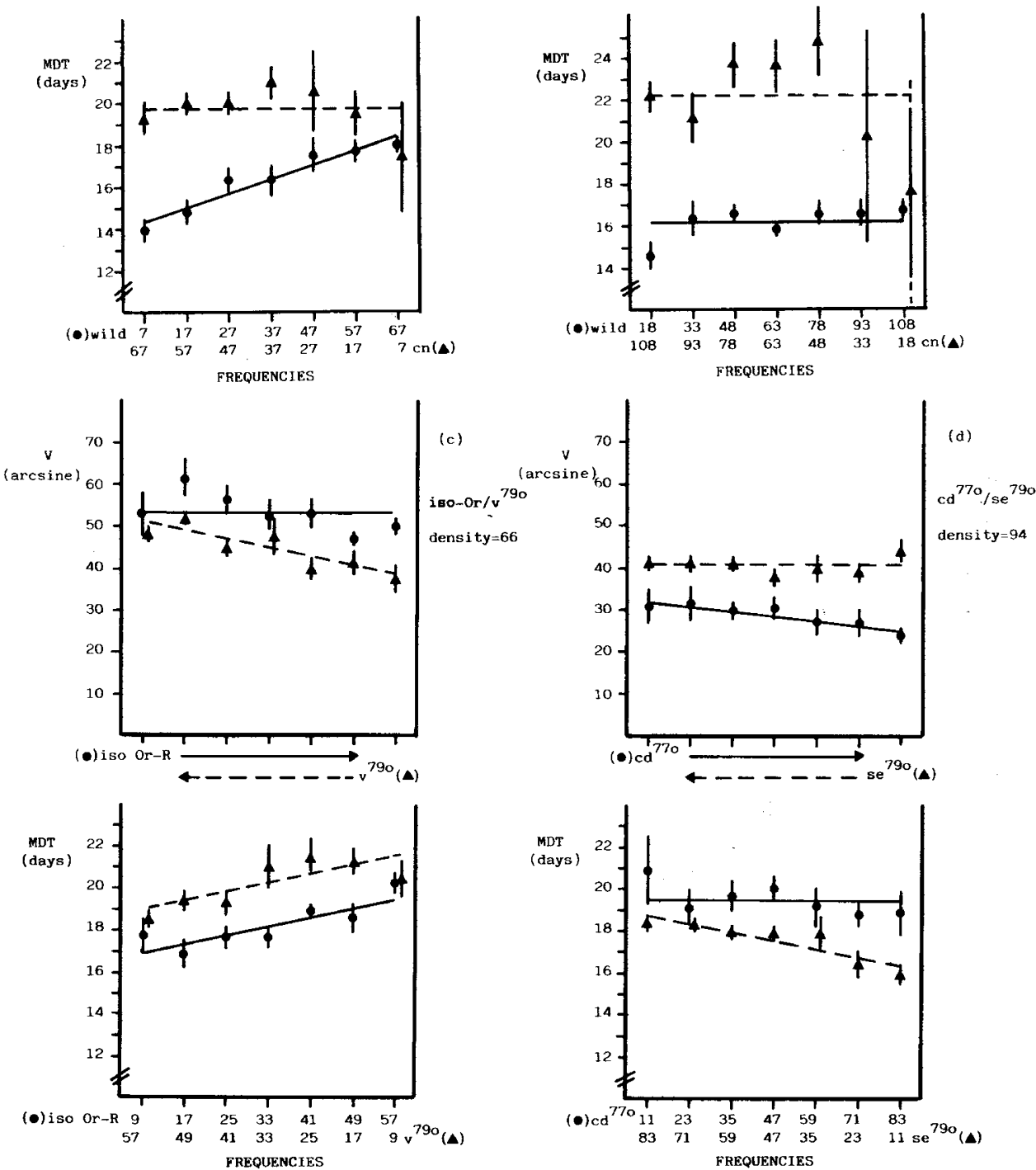


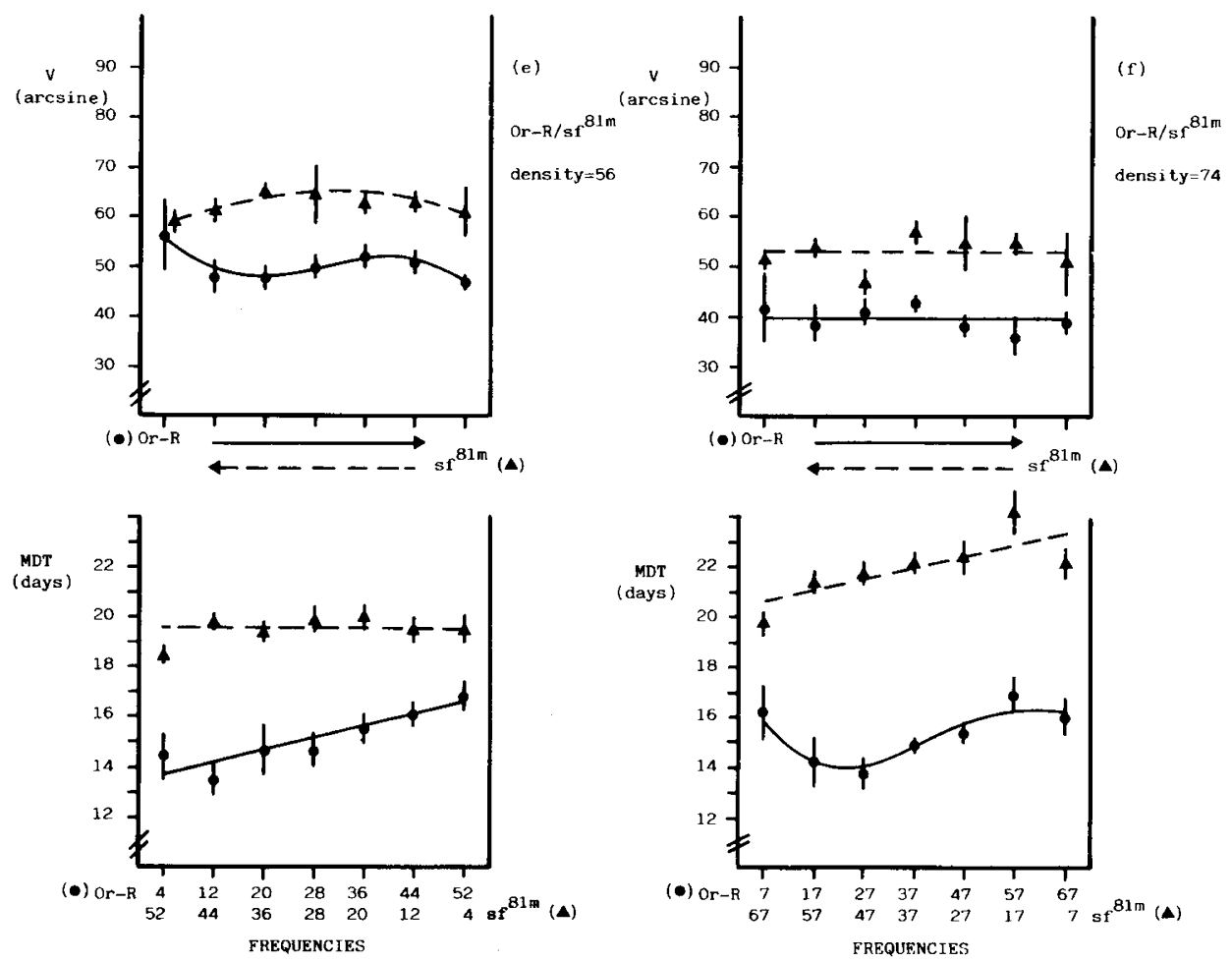

FIG. 1

Viability $(V)$ given in arcsine transformation, and mean developmental time $(M D T)$ in the 6 competition systems over their corresponding frequency ranges : wild/cn at density of $74(a)$ and of $126(b)$; iso-Or $/ v^{790}$ at a density of $66(C) ; c d^{770} / s^{790}$ at a density of $94(d) ; O r-R / s f^{81 m}$ at a density of $56(e)$ and of $74(f)$.

In this figure there are constancies, linear regressions and polynomial regressions in both $V$ and $M D T$. These fits are the results of the analyses of variance completed with polynomial regressions (see Material and Methods, section D for more details).

Table 2 shows the results of uric acid quantitative determinations for every strain. The analysis of variance showed significant differences among strains at all stages and levels of crowding. The difference in the concentration found between pupae and larvae can be explained by the lack of external excretion in pupae. In order to search for those strains of identical fitness from a statistical point of view, a test of StudentNewman-Keuls (SoKal \& Rohlf, 1969) was applied (table 3). This test groups in the same set those strains whose uric acid concentrations are not statistically different from each other ; this analysis is applied to each stage of crowded and uncrowded situations. In the crowded situation, at the larval stage the $\mathrm{cd}^{770}, \mathrm{cn}$, wild, $\mathrm{v}^{7 \% 0}$, $\mathrm{sf}^{81 \mathrm{~m}}$ and $\mathrm{se}^{7 \%}$ strains have no differences among them, Or-R being the strain with the most uric acid at this stage. At the pupal stage this test selected 4 subsets. It is interesting to see that $\mathrm{sf}^{81 \mathrm{~m}}$ and $\mathrm{se}^{7 y_{0}}$ are statistically different from $\mathrm{v}^{790}, \mathrm{cn}, \mathrm{cd}^{770}$, iso-Or and wild strains, with Or- $R$ being the strain with the most uric acid. In the media, the test selected 3 subsets, the 1 st with the $\mathrm{sf}^{81 \mathrm{~m}}, \mathrm{~cd}^{770}$, wild, $\mathrm{cn}$ and iso-Or strains, the $2 \mathrm{nd}$ with the $\mathrm{se}^{7 \mathrm{yo}_{0}}$ and Or-R 


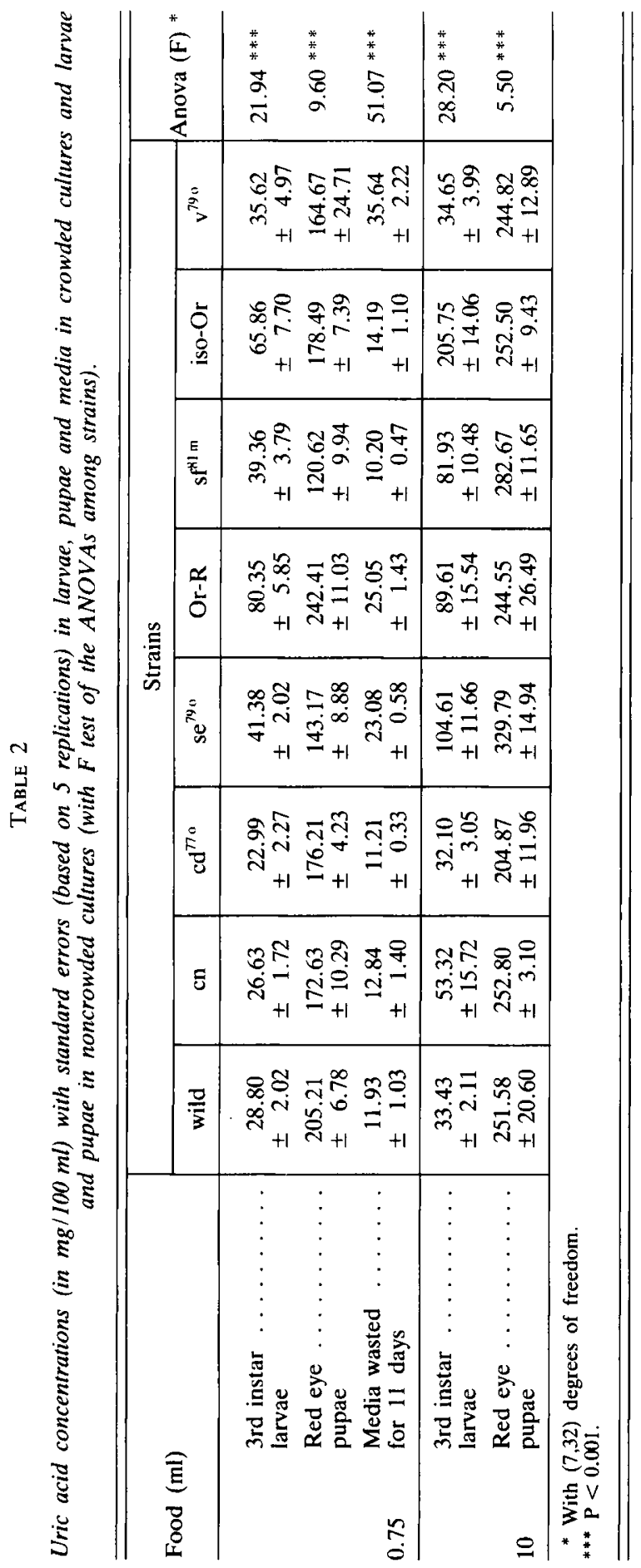




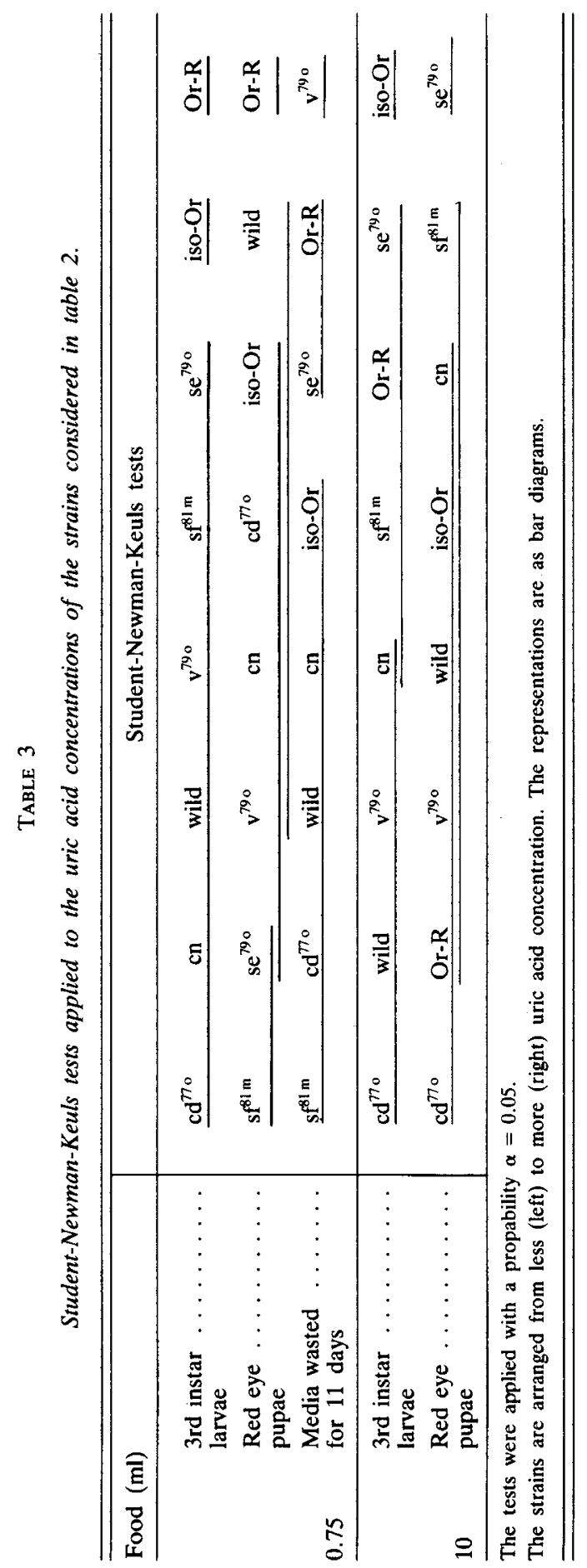


strains, $\mathrm{v}^{790}$ being the strain that excretes the most uric acid. In non-crowded conditions, at the larval stage 4 subsets are selected, the 1 st with $\mathrm{cd}^{770}$, wild, $\mathrm{v}^{790}$ and $\mathrm{cn}$ strains ; the 2nd with $\mathrm{cn}$, $\mathrm{sf}^{81 \mathrm{~m}}$ and Or-R strains, the 3rd with $\mathrm{s}^{81 \mathrm{~m}}$, Or-R and $\mathrm{se}^{790}$ strains, with iso-Or the strain with the most uric acid. At the pupal stage, 3 subsets are selected, but practically all strains have the same uric acid except $\mathrm{se}^{790}$.

In table 4 is presented the two-way analysis of variance (strains versus larvae/ media wasted) of the strains concerned in the competitive systems to study the interaction between uric acid concentration in larvae and media in crowded cultures. When wild and cn strains are compared, we found that uric acid excretion in both strains is similar. In iso-Or and $\mathrm{v}^{790}$ strains, there is a significant interaction ; in fact, $\mathrm{v}^{790}$ has less uric acid in larvae than iso-Or, but it excretes more to the medium (see table 2). In $\mathrm{cd}^{770}$ and $\mathrm{se}^{790}$ strains, the interaction is not significant and it means that $\mathrm{cd}^{770}$ has less uric acid than $\mathrm{se}^{790}$ and it also excretes less than $\mathrm{se}^{790}$ into the medium, but both strains excrete in a similar proportion. With regard to Or-R and $\mathbf{s f}^{81 \mathrm{~m}}$, there is a significant interaction; indeed, the Or- $R$ strain has more uric acid in larvae than $\mathbf{s f}^{81 \mathrm{~m}}$, but it excretes less into the medium proportionately than $\mathbf{s f}^{8 \mathrm{~m} m}$. These results are important to explain the competitive systems carried out later with these strains.

TABLE 4

Two-way analysis of variance (strains versus larvae-media wasted) of the strains concerned in the competitive systems (S.V. = Source of variation. S.S. = Sum of squares. D.F. = Degrees of freedom. M.S. = Mean square. $A=$ Strains. $B=$ Larvae-media wasted).

\begin{tabular}{|c|c|c|c|c|c|}
\hline Strains & S.V. & D.F. & S.S. & M.S. & $\mathbf{F}$ \\
\hline wild/cn .... & $\begin{array}{l}\text { Subgroups } \\
\text { A } \\
\text { B } \\
\text { A } \times \text { B } \\
\text { Error } \\
\text { Total }\end{array}$ & $\begin{array}{r}3 \\
1 \\
1 \\
1 \\
16 \\
19\end{array}$ & $\begin{array}{r}1323.4 \\
11.1 \\
1309.9 \\
2.4 \\
250.0 \\
1573.4\end{array}$ & $\begin{array}{r}441.1 \\
11.1 \\
1309.9 \\
2.4 \\
15.6\end{array}$ & $\begin{array}{r}0.71^{\text {n.s. }} \\
83.84^{* * *} \\
0.15^{\text {n.s. }}\end{array}$ \\
\hline Iso-Or $/ v^{79 o} \ldots$ & $\begin{array}{l}\text { Subgroups } \\
\text { A } \\
\text { B } \\
\text { A } \times \text { B } \\
\text { Error } \\
\text { Total }\end{array}$ & $\begin{array}{r}3 \\
1 \\
1 \\
1 \\
16 \\
19\end{array}$ & $\begin{array}{rr}6 & 751.3 \\
& 76.4 \\
3 & 208.6 \\
3 & 466.3 \\
1 & 795.0 \\
8 & 546.4\end{array}$ & $\begin{array}{r}2250.4 \\
76.4 \\
3208.6 \\
3466.3 \\
112.2\end{array}$ & $\begin{array}{c}0.68^{\text {n.s. }} \\
28.60^{* * *} \\
30.90^{* * *}\end{array}$ \\
\hline $\mathrm{cd}^{77 o} / \mathrm{se}^{79 o} \ldots$ & $\begin{array}{l}\text { Subgroups } \\
\text { A } \\
\text { B } \\
A \times B \\
\text { Error } \\
\text { Total }\end{array}$ & $\begin{array}{r}3 \\
1 \\
1 \\
1 \\
16 \\
19\end{array}$ & $\begin{array}{rr}2 & 328.4 \\
1 & 145.2 \\
1 & 130.1 \\
& 53.1 \\
& 193.7 \\
2 & 522.1\end{array}$ & $\begin{array}{rr} & 776.1 \\
1 & 145.2 \\
1 & 130.1 \\
53.1 \\
12.1\end{array}$ & $\begin{array}{c}94.60^{* * *} \\
93.35^{* * *} \\
4.38^{\text {n.s. }}\end{array}$ \\
\hline Or-R/sf ${ }^{81 \mathrm{~m}} \ldots$ & $\begin{array}{l}\text { Subgroups } \\
\text { A } \\
\text { B } \\
\text { A } \times \text { B } \\
\text { Error } \\
\text { Total }\end{array}$ & $\begin{array}{r}3 \\
1 \\
1 \\
1 \\
16 \\
19\end{array}$ & $\begin{array}{r}13666.4 \\
3897.6 \\
8914.3 \\
854.4 \\
1018.0\end{array}$ & $\begin{array}{r}4555.5 \\
3897.6 \\
8914.3 \\
854.4 \\
63.6\end{array}$ & $\begin{array}{r}61.26^{* * *} \\
140.11^{* * *} \\
13.43^{* *}\end{array}$ \\
\hline
\end{tabular}

n.s. : not significant.

**: $\mathrm{P}<0.005$.

***: $\mathrm{P}<0.001$ 

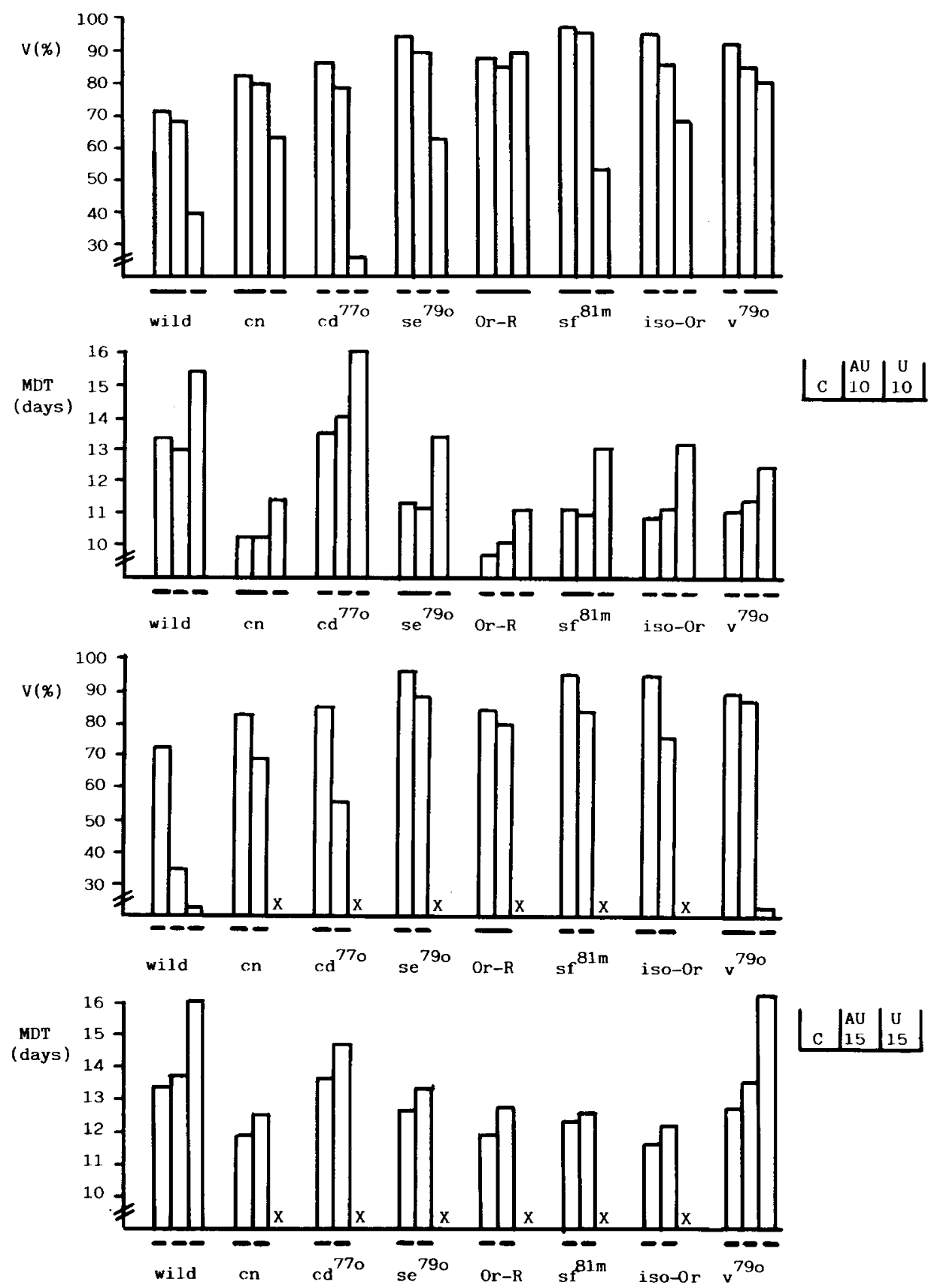

Fig. 2

Viability $(V)$ and mean developmental time $(M D T)$ in the different strains, in media supplemented with 10 and $15 \mathrm{mg} / \mathrm{ml}$ of uric acid or urea, in relation to a control $(C)$.

$\mathrm{AU} 10$ and $\mathrm{AU} 15$ stand for 10 and $15 \mathrm{mg} / \mathrm{ml}$ of uric acid, respectively, and $\mathrm{U} 10$ and $\mathrm{U} 15$ for 10 and $15 \mathrm{mg} / \mathrm{ml}$ of urea. X means that no adult recovery took place. In the bottom of each figure appears the SNK tests as bar diagrams (with a probability $\alpha=0.05$ ). 
Figure 2 shows the results for viability and mean developmental time in the different strains in control media and media supplemented with 10 and $15 \mathrm{mg} / \mathrm{ml}$ of uric acid or urea ; in the bottom of each figure the SNK tests appear as bar diagrams. Uric acid and urea are toxic to larvae because they lower viability and delay developmental time. The low solubility of the uric acid in the medium and the high solubility of the urea must be considered, since CASTRo et al. (1986) showed that this solubility is 2 orders of magnitude lower than the quantity added to the medium. Thus the results obtained with the added uric acid and urea were not exactly comparable. A level of $10 \mathrm{mg} / \mathrm{ml}$ of uric acid significantly decreased viability in the cardinal, sepia, iso-Or and vermilion strains. This dose significantly delayed mean developmental time of cardinal, Or-R, iso-Or and vermilion strains. A dose of $15 \mathrm{mg} / \mathrm{ml}$ lowered viability in all strains except $\mathrm{Or}-\mathrm{R}$ and vermilion, and it lengthened significantly mean developmental time in all strains though only slightly in wild and safranin. Urea at $10 \mathrm{mg} / \mathrm{ml}$ lowered viability in all strains except Or- $R$, and lengthened mean developmental time in all strains. At $15 \mathrm{mg} / \mathrm{ml}$ viability was practically nil in all strains. In the wild and vermilion strains which showed some degree of survival, mean developmental time was extremely long.

In conclusion the Or- $\mathrm{R}$ strain appears to be the most resistant to biotic residues, since only $15 \mathrm{mg} / \mathrm{ml}$ of urea lowered its viability. Other resistant strains include wild, cinnabar, safranin and vermilion. The cardinal, sepia and iso-Or strains seem to be most sensitive, particularly with respect to viability.

\section{Discussion and conclusion}

The complexity of intragenotypic competition is evident from the non-linear regressions of viability and developmental time. One could simplify by considering only linear fits. This simplification may be adequate to demonstrate the existence of a new phenomenon, but it does not provide a complete explanation.

Phenomena such as facilitation (Lewontin, 1955) at low densities, or " chaos zone » behaviour at high densities (HASSELl et al., 1976) help us to a better understanding of the competitive processes along an increasing density range, and the existence of non-linear regression fits.

In spite of the fact that Wallace's unit biological space model (WALLACE, 1981) had been applied by Wallace primarily to plants it is helpful in the interpretation of our results. The response of strains when competing simultaneously may be interpreted with the aid of $k$ unit spaces (value deduced from optimal density). A strain with high optimal density has a large number of unit spaces available, and therefore, it can make use more efficiently of food and space. From a reductionist point of view, the strain with the highest optimal density would exclude its competitor, but we must take into account that optimal densities change over time (see table 1) and so, this parameter must be applied with care and precaution, and considering the optimal densities which strains have at the specific time of the competition experiments. Moreover, interactions among strains appear in competition processes. These interactions reflected in the coefficients of intergenotypic competition may change the predictions made from strains considered individually in monocultures, and these coefficients in some instances may reflect hidden capacities only manifested in intergenotypic competition (WALLACE, 
1974 ; Mather \& Caligari, 1983). One of the parameters which may account for the superiority or inferiority of strains is their higher or lower resistance to larval biotic residues which pollute the competition media. Although the presence of other biotic residues cannot be ruled out, attention was focused on uric acid because of its noxious effect on larvae, and because high levels accumulate in crowded cultures (Botella et al., 1985). Urea effects were also studied.

Although we have studied in this paper the effect of uric acid and urea in monocultures, the extrapolation of these effects to competitive systems is possible. In a recent paper, (CASTRO et al., 1986) demonstrated the importance and effect of uric acid (among other factors) in intergenotypic competition by means of the conditioned media technique. Moreover, we have carried out an experiment (CASTRo et al., 1987) which demonstrated the additive effect of uric acid excreted to the medium by larvae of 2 different strains in competitive situations.

In the wild/cinnabar system (fig. 1a, b), a clear advantage of wild (in viability and mean developmental time) was observed. The higher viability of cinnabar in monocultures was not translated to dicultures. The more rapid developmental rate of wild seems to be responsible. In monocultures, wild developed faster than cinnabar from a density of 65 on, and at the densities of 74 and 126, which have been employed in dicultures, this superiority of wild is maintained. If wild develops quicker than cinnabar, it would occupy the unit biological spaces available far sooner than cinnabar. Therefore, the cinnabar strain would not be able to develop their unit biological space strategy because many of these units will already be occupied by its competitors.

The equilibrium point found in viability can be explained by the intragenotypic competition of wild. Wild is positively frequency-dependent in mean developmental time. Cinnabar, however maintains a constant response at all frequencies, and is always more delayed in development than wild. These factors suggest that intragenotypic competition, at least in wild, is very important. At high frequencies of this strain, wild competes with itself and lowers its viability. On the contrary, the constancy found in viability and mean developmental time in the cinnabar strain points out that intragenotypic competition is not so important as in wild.

When competition is not strong (fig. 1a) a stable point of equilibrium may be established. The density of 126 seems to be a situation of very strong competition for both strains. At this density (126) a hard selection situation (WALlaCE, 1975) may be hiding a type of soft selection apparent at lower densities. At the density of 126 , the total viability of the system was lower than at the density of 74 , and mean developmental time in general was lengthened. The mean developmental time of wild was quite constant throughout the frequency range, while mean developmental time in cinnabar was somewhat erratic at the 2 lowest frequencies. Perhaps cinnabar was affected more than wild by this hard selection.

With respect to viability, wild keeps its negative frequency-dependent selection pattern shown at a density of 74 , thus reflecting its intragenotypic competition, while cinnabar keeps its inferiority with respect to wild, it being carried by wild. When wild was at low density, viability in cinnabar increased.

In the iso-Or/vermilion system (fig. 1c) we find another case of superiority in competition. In monocultures, vermilion was superior in optimal density, resistance to biotic residues and excreted more uric acid, factors which in principle are all favourable for superiority. Mean developmental time in iso-Or was faster than vermilion in 
monocultures at all densities except 50,65 and 80. In dicultures vermilion was inferior to iso-Or in both viability and mean developmental time. The explanation of this system may be the same as in the previous system. If iso-Or develops faster than vermilion, it will occupy biological space units before its competitor. Vermilion will then be displaced since it cannot make use of food resources as well as when alone. This would explain why iso-Or is not affected by biotic residues from vermilion. In fact, when the amount of biotic residues excreted by vermilion begins to be important, isoOr larvae might be sufficiently advanced in their development or even in the pupal stage, avoiding in this way the effect of these residues.

The iso-Or strain showed positive frequency-dependent response in mean developmental time, which may indicate a certain degree of intragenotypical competition, but not enough, however, to affect viability. The vermilion strain was carried by iso-Or ; its mean developmental time was faster at low frequencies of iso-Or; and had also an increase in viability when iso-Or was at a lower frequency.

In the cardinal/sepia system (fig. 1d), the sepia strain showed a response in dicultures in accord with predictions based on monocultures. Its optimal density was higher and it had more resistance towards biotic residues than cardinal (see fig. 2). Mean developmental time was similar in monocultures in both strains. Moreover, sepia excretes more uric acid, which in turn is more noxious to cardinal. In this system, competition coefficients may be markedly influenced by biotic residues and the parameters deduced from monocultures. Cardinal seems to have an important intragenotypic competition since its viability was lowest at the highest frequencies. The same was true in sepia with respect to mean developmental time, though viability was not affected.

In the Or-R/safranin system (fig. 1e,f) safranin exhibited superior viability for both densities, but Or-R is faster than safranin as in monocultures. This system seems to be quite complex, since safranin has a higher optimal density and a lower intrinsic mortality than Or-R. Yet, Or-R is more resistant with respect to biotic residues and excretes greater amounts of uric acid than safranin. At a density of 56 (fig. 1e), biotic residues did not appear to have a major effect (perhaps the threshold necessary for biotic residues exercising their effect has not been reached at this low density).

Intergenotypic competitive coefficients cannot be explained in this system as a simple linear combination of the parameters studied in monocultures (such as viability, developmental time and biotic residues). Interactions must be more complex and involve other factors not taken into account such as food assimilation, minimum weight for pupation, or humidity (CAsrro et al., 1986). These factors might explain the response of the Or- $R$ strain in dicultures because the adults of Or- $R$, which are successful from competition, will emerge soon ; lowering in this way its mean developmental time relative to the safranin strain. Theoretically, the possibility of more than one equilibrium point in competition can exist (AnXolabehere \& Periquet, 1981; Cockerham et al., 1972). However, in practice these points are difficult to find. In this system, the 3rd order fits found would permit more than one equilibrium point. If competitive abilities of the Or-R and safranin strains were more similar these points might have appeared.

In general, one can draw the following conclusions :

(1) The dynamics of monocultures can be explained relative to intrinsic mortality and optimal density, using Wallace's unit biological space model, as well as by considering the influence of biotic residues (MoyA \& CASTro, 1986). 
(2) Optimal densities are not fixed parameters but change over time depending on the fitness of a strain at a given moment ; for this reason, they must be calculated at the same time that the competitive systems are carried out.

(3) In competitive situations, moreover intrinsic mortality and optimal density, we must take into account the coefficients of intergenotypic competition. One important component of these coefficients is larval biotic residues.

(4) Other components take part of the coefficient of competition and could be deduced from the study of the monocultures of a given strain, though the emergent properties of competing systems must be taken into account.

(5) The existence of higher than linear order polynomial regressions in competition systems permits the possibility of more than one equilibrium point. These points, however, have not been found in this study.

Received July 21, 1986.

Accepted January 5, 1987.

\section{Acknowledgements}

The authors are greatly indebted to 2 anonymous reviewers for valuable comments in the revision of the manuscript. It has been greatly improved with these comments.

\section{References}

ANScombe F.J., 1948. The transformation of Poisson, binomial and negative binomial data. Biometrika, 35, 246-254.

Anxolabehere D., Periquet G., 1981. The role of frequency-dependent selection in the outcome of experimental populations in evolution. Genetica, 55, 3-9.

Ayala F.J., Campbell C.A., 1974. Frequency-dependent selection. Ann. Rev. Ecol. and Syst., 5, 115-137.

Botella L.M., Moya A., Gonzalez C., Mensua J.L., 1985. Delayed development, low survival and larval stop in Drosophila melanogaster : effect of urea and uric acid. J. Insect. Physiol., 31, 179-185.

Caligari P., 1980. Competitive interactions in D. melanogaster. I. Monocultures. Heredity, 45, 219-231.

Castro J.A., Moya A., Mensua J.L., 1985. Competitive selection in mono-, di- and tri-genotype cultures of D. melanogaster. Z. Zool. Syst. Evolut.forsch., 23, 214-228.

Castro J.A., Botella L.M., Mensua J.L., 1986. Effect of conditioned media on three genotypes of Drosophila melanogaster : physical, chemical and biological aspects. Arch. Insect Biochem. and Physiol., 3, 485-497.

Castro J.A., Botella L.M., Mensua J.L., 1987. Non-interaction in larval uric acid excretion in competition systems of Drosophila melanogaster. GPOLA (in press).

Clarke B., O’Donald P., 1964. Frequency-dependent selection. Heredity, 19, 201-206.

Cockerham C.C., Burrows P.M., Young S.S., Prout T., 1972. Frequency-dependent selection in randomly mating populations. Am. Nat., 106, 493-515. 
DE BenEdictis P.A., 1977. The meaning and measurement of frequency-dependent competition. Ecology, 58, 158-166.

Dolan R., Robertson A., 1975. The effect of conditioning the medium in Drosophila in relation to frequency-dependent selection. Heredity, 35, 311-316.

Hassell M.P., Lawton J.H., May R.M., 1976. Patterns of dynamical behaviour in single-species populations. J. Anim. Ecol., 45, 471-486.

Huang S.L., Sing M., KoJIma K.I., 1971. A study of frequency-dependent selection observed in the esterase-6 locus of Drosophila melanogaster using a conditioned media method. Genetics, 68, 97-104.

Lewontin R.C., 1975. The effects of population density and composition on viability in Drosophila melanogaster. Evolution, 9, 27-41.

Lewontin R.C., 1985. Population Genetics. Ann. Rev. Genet., 19, 81-102.

Mather K., Caligari P., 1981. Competitive interactions in Drosophila melanogaster. II. Measurement of competition. Heredity, 46, 239-254.

Mather K., Caligari P., 1983. Pressure and response in competitive interactions. Heredity, 51, 435-454.

Moya A., 1983. Estudios de selección competitiva intra- $e$ intergenotípica durante el desarrollo larvario de Drosophila melanogaster. Ph. D. Thesis, Valencia.

Moya A., Castro J., 1986. Larval competition in Drosophila melanogaster: The model of the bands of density. Oikos, 47, 280-286.

NAJERA C., 1985. Variabilidad de mutaciones que afectan al color de los ojos en poblaciones naturales y experimentales de Drosophila melanogaster. Ph. D. Thesis, Valencia.

Palabost L., 1973. Inhibition et facilitation du développement lors de la mise en compétition de deux souches de Drosophila melanogaster. Arch. Zool. Exp. Gén., 114, 491-512.

SNedecor G.W., Cochran W.G., 1981. Métodos estadísticos. 703 p. Compañía Editorial Continental, S.A. México (translated from the 6th edition of Stasistical methods). The Iowa State University Press, Ames, Iowa.

SoKal R.R., RohlF F.J., 1969. Biometry. 776 p., Freeman, San Francisco.

Tosic M., Ayala F.J., 1981. Density- and frequency-dependent selection at the Mdh-2 locus in $D$. pseudoobscura. Genetics, 97, 679-701.

Wallace B., 1974. Studies on intra- and inter-specific competition in Drosophila. Ecology, 55, 227-244.

WALlACE B., 1975. Hard and soft selection revisited. Evolution, 29, 465-473.

Wallace B., 1981. Basic population genetics. 688 p., New York, Columbia University Press.

Wilson D.S., 1980. The Natural Selection of Populations and Communities. 186 p., The Benjamin/ Cumming Publishing Company, Inc. Menlo Park. California. 